\title{
E-commerce Virtual Business Circle Build upon Big Data Base
}

\author{
Linlin Lu \\ Huaxin College, Shijiazhuang University of Economics, 050700, Hebei Province, China
}

Keywords: E-commerce; virtual business circle; huff's model.

\begin{abstract}
The research, take the most representative of Chinese e-commerce platform Taobao for example, discussed how to establish virtual values of electronic commerce by data mining method. Based on the characteristics of Taobao business, huff's model is applied to the Taobao. Sellers in the same industry were calculated in the same region, and I analyzed the advantages and disadvantages of electricity business model for Taobao.
\end{abstract}

\section{Introduction}

\subsection{The advantage of the present}

In the digital era, e-commerce dig out commercial value by the collection analysis and integration of the massive data about businesses and consumers. It promoted personalized and precision marketing. E-commerce enterprises have great prospects for development in the development and utilization of the big data market. If the big data technology has been applied in Electronic commerce, the probability would be significantly improved in which we find potential customers, predict sales time and the success of the transaction.

Use Internet technology widely in e-commerce, which made Electronic Business without geographical position. Covering the range of e-commerce expand around the world with the popularity of the network. The modern logistics and express emerged with a strong power. Necessarily, it is realistic that the transaction retail e-commerce quickly is completed in the range covered by express delivery.

The profitability of business isn't limited by geographical position of consumers and consumers of transportation.

\subsection{The difficulties of electronic commerce development}

Taobao is the most representative of Chinese e-commerce platform. Taobao development was going through a difficult time at the present stage. More and more small and medium enterprises failed in electronic commerce. On 21th-July-2013, Economic observer randomly selected from more than 100 sellers in Taobao.

Through 75 valid questionnaires, we discovered that more than $90 \%$ of shops' operation time are not over 3 years, $60 \%$ of shops operation time are less than 2 years, and about $30 \%$ of shops are over 1 year. This meaning that there are a lot of businesses smaller companies with briefer operating histories in Taobao. These companies need to take some time to build credibility and performance. In addition, the sales team was nearly half of all operators that is less than 3 persons, 46 persons sales team was only accounted for a third of all companies, other sales team has 8 persons that is one fifth( Reference on July 21, 2013, the economic observer, the newspaper provided the data).

90\% small and medium enterprises of Taobao failed in inventory risk. Those enterprises only make large orders and large inventory if average cost can reduce, it will make a great inventory risk. Therefore, small and medium enterprises have to make many batches and a little amount of orders. Cut-throat competition and promotion expenses make low prices and high coast. Hence, the difficulties make shops without profitability.

Because the electronic commerce is virtual, consumers can go to pick commodity by introduction of goods and other consumer reviews. That causes the product quality to be uneven, and appear even the fake and inferior products. There are some really great qualities and low prices stores to be buried in a large number of stores with brushed out the high credibility. 


\subsection{The introduction of huff's model}

In this paper, Mathematical model is huff's model.

In 1964, the American scholar Huff research Business Circle theory model that was based on the store as a unit. It aims to examine the possibility of customers to a retail shopping, and it according to this measure the scope of the business circle.

The model can be expressed as

$$
P_{i j}=\frac{S_{j}^{\mu} / T_{i j}^{\mu}}{\sum_{j=i}^{n} \frac{S_{j}^{\mu}}{T_{i j}^{\lambda}}}
$$

Huff customer attraction model show that the bigger than a competing retail store, the higher risk of customers to go to the store shopping. For consumers, large shops have more goods to choose; for competitors, the customer shopping coast longer time or farther distance, the possibility of customers to the store shopping is less.

\section{METHOD}

We mainly discussed two cases which were Business to Business and Business to Costumers in the paper.

$$
P_{i j}=\frac{S_{j}^{\mu} / T_{i j}^{\mu}}{\sum_{j=i}^{n} \frac{S_{j}^{\mu}}{T_{i j}^{\lambda}}}
$$

$\mathrm{P}_{i j}=$ the Probability of consumers from region $\mathrm{i}$ to store $\mathrm{j}$ shopping;

$S_{j}=$ attraction of $\mathrm{j}$ store;

$T_{i j}=$ resistance of distance from region $\mathrm{i}$ to store $\mathrm{j}$;

$\mathrm{n}=$ the number of factories in the same region or industry;

$\mu$ generally equal to 1 ;

$\lambda$ generally equal to 2 .

Suppose conditions:

The area of the store doesn't influence the results;

Express doesn't matter shopping rate of the consumers;

We can establish Virtual Business Circle in the same province.

Assume one factor, Attraction Index (a) $=S_{j} / T_{i j}$

Procurement can accurately describe a;

Attraction index (a) is actually in proportion to purchase volume;

So, attraction Index (a) could substitute for purchase volume.

The result is the logic of deductive reasoning, as: $a=b, b=c, a=c$.

\section{Results}

The report breaks down the results region by region.

A month's purchases among regions on Wednesday, February 11, 2015

1 Suzhou City of Jiangsu Province 61,906

2 Guangzhou City of Guangdong Province 23,628

3 Shenzhen City of Guangdong Province 13,182

4 Dongguan City of Guangdong Province 12,944

5 Hangzhou City of Zhejiang Province 8,141

6 Chaozhou City of Guangdong Province 4,560

7 Wenzhou City of Zhejiang Province 4,219

8 Huaian City of Jiangsu Province 4,009

9 Zhongshan City of Guangdong Province 3,980

10 Shanghai 2,329 
$\Sigma S_{j} / T_{i j}=138898$

$\Sigma$ Guangdong Province $=58294$

PGuangdong Province $=41.97 \%$

¿Jiangsu Province $=65915$

PJiangsu Province $=47.46 \%$

$\mathrm{P}$ of Jiangsu province and Guangdong province is approximately equal. If Virtual Business Circle is set up in Guangdong province, the rate that consumers choose Guangdong province is closely equal. Actually, the plan is practical.

Suzhou city is strongly competitive that it is difficult for other cities to be contending with in Jiangsu province. E-commerce Virtual Business Circle is established in Guangzhou City, that could necessarily improve Virtual Business Circle competitive power and small and medium enterprises could survive for longer time.

We can establish E-commerce Virtual Business Circle in Guangdong province, which makes Guangdong province contend with competitive power of industrial base, Suzhou in Jiangsu province.

\section{Conclusion}

\subsection{The theory of virtual business circle in e-commerce}

With the rapid development of E-commerce, consumers can browse different retail's merchandise and price without leaving home. And consumers can fully enjoy the preferential services which businesses provide consumers.

There has seen a great change in the coverage of Business Circle. It depends on more than the geographic position. And the tastes of consumers in the network, price and customers service influence the coverage a lot. Comparing the sales volume can predict the consumers' trend and establish virtual business circle.

The theory and advantage of virtual business circle: when the basic value of subje services are more accessible to a wider range of customers. Therefore, the supporting facilities and service of the circle must be perfect. And potential customers become real. Subject and object which will be attracted by the circle will have a higher expectation. The utility of subject and object will be improved, when more subject and object enter the circle. Merchants compete with each other in the business circle. However, they share the market information and also that can reduce the risk of a certain market. Business circle can provide better service to customers, and can save time cost of consumers to purchase goods. The focus of the competition is no longer the price. Merchants can gain advantage by improving the pre-sale service and after-sale service and improving quality of products.

\subsection{How to solve problems}

We can use some methods to improve this situation. Those are my suggestions:

Establish a consortium in same region.

Ensure the quality of commodities and service. Because of the network and position advantages, Merchants trust each other in the same province and in the same industry. Merchants should voluntarily signed guarantee about product quality and pre-market after-sales service in one consortium, and consciously perform and supervise each other. The consortium's good reputation is built in consumers of Taobao.

Partnership management of warehouse. Partnership management of warehouse--Parts manufacturers provide warehouse, manufacturers provide logistics management and some manufacturers to provide funds. They are mutual cooperation and mutual supervision.

That can reduce inventory risk. The modal is a combination of reality and electronic commerce. It will use the adjacent location, and that can reduce inventory risk.

Small and medium enterprises share the same warehouse.

This will reduce the inventory cost. A part of manufacturers can achieve cargo reassignment between each other, so we can increase sales. 


\section{REFERENCES}

[1] LIU Jiang. The Research of Virtual Business Circle; [D]. Huaqiao University, 2009.

[5] LV Qing-hua, LIU Jiang. Economic Analysis of the Retailing Virtual Business Circle [J]. Economic problems, 2009 (4): 109-111.

[6] Xu Li-juan. Study on the business circle on E-business [J]. Logistic Techology, 2006 (11): 2324. 